\title{
Preface to the Proceedings of the European General Assembly and the United Nations Workshop
}

\author{
N. Gopalswamy · G. Eichhorn $\cdot$ T. Sakurai $\cdot$ H. J. Haubold
}

Received: 24 October 2008/Accepted: 24 October 2008/Published online: 8 January 2009

(C) Springer Science+Business Media B.V. 2009

From 6 to 15 June 2007 the Committee of the Peaceful Uses of Outer Space (COPUOS) held its fiftieth session in Vienna, Austria, marking the important convergence of anniversaries, which include the 50th anniversary of space age, the 40th anniversary of the entry into force of the Outer Space Treaty and the celebration of International Heliophysical Year 2007 (IHY 2007). COPUOS, which is the only permanent UN body that deals exclusively with peaceful uses of outer space, was established in 1958 as an ad hoc committee by the UN General Assembly resolution 1348, which noted the success of the scientific co-operative programme of the International Geophysical Year (IGY 1957) in the exploration of outer space and decided to continue and expand this type of cooperation. In 1959, the Committee became a permanent body with a mandate to review the scope of international cooperation in the peaceful uses of outer space, devise programmes in this field to be undertaken under UN auspices, encourage continued research and the dissemination of information on outer space matters and to study legal problems arising from the exploration of outer space. Alone to write the history of achievements of this Committee in the past 50 years would need considerable scholarship on part of historians (http://www. unoosa.org/oosa/events/copuos50.html).

The UN General Assembly, in its resolution 60/99 of 2005, noted with satisfaction the contribution being made by the Scientific and Technical Subcommittee of COPUOS and the efforts of Member States and the Office for Outer Space Affairs (OOSA) to promote

\footnotetext{
N. Gopalswamy · G. Eichhorn · T. Sakurai · H. J. Haubold ( $\square)$

UN Office for Outer Space Affairs, Vienna International Centre, Wagramerstr. 5,

P.O. Box 500, 1400 Vienna, Austria

e-mail: hans.haubold@unvienna.org

N. Gopalswamy

Solar System Exploration, Code 695, NASA Goddard Space Flight Center, Greenbelt, MD 20771, USA

G. Eichhorn

Springer Director, Abstracting and Indexing, 101 Philip Drive, Norwell, MA 02061, USA

T. Sakurai

National Astronomical Observatory, 2211 Osawa Mitaka, Tokyo 181, Japan
} 
and support the activities being organized within the framework of IHY 2007 in the spirit of IGY 1957. IHY 2007 is now taken as an opportunity to (i) advance the understanding of the fundamental heliophysical processes that govern the Sun, Earth, and heliosphere, (ii) continue the tradition of international research and advancing the legacy of IGY 1957, and (iii) demonstrate the beauty, relevance and significance of space and Earth science to the world (http://ihy2007.org, see also J. Davila et al. Space Policy 23(2007)121-126).

In preparation of IHY 2007, the OOSA (http://www.unoosa.org/oosa/en/SAP/bss/ ihy2007/index.html), in cooperation with NASA, ESA, and the IHY Secretariat, hold international workshops in the United Arab Emirates in 2005 (http://www.ihy.uaeu.ac.ae/), in India in 2006 (http://www.iiap.res.in/ihy/), and at the National Astronomical Observatory of Japan in Tokyo, 18-22 June 2007 (http://solarwww.mtk.nao.ac.jp/UNBSS_ Tokyo07/). The starting date of IHY 2007 was February 19, 2007. On that date, during the session of the Scientific and Technical Subcommittee of COPUOS, the IHY kick-off included an IHY exhibit, press briefing, and an opening ceremony in the United Nations Office Vienna (http://ihy2007.org/newsroom/opening_ceremony.shtml). IHY regional coordinators, Steering Committee members, and Advisory Committee members participated in the IHY kick-off event. The Austrian Academy of Sciences hosted a one-day symposium on IHY 2007 in Vienna on 20 February 2007. IGY 1957 was one of the most successful international science programmes of all time and broke new ground in the development of space science and technology. Fifty years later, IHY 2007 continues this tradition. The tradition of international science years began almost 125 years ago, when the first international scientific studies of global processes of the Earth's poles took place from 1882 to 1883 . A second International Polar Year was organized in 1932, but a worldwide economic depression curtailed many of the planned activities.

Many of the IHY 2007 participants hope for an amplification of their efforts when humanity will celebrate the International Year of Astronomy in 2009 (http://www. astronomy2009.org/). 